\title{
Comparison of Monthly Ibandronate Versus Weekly Risedronate in Preference, Convenience, and Bone Turnover Markers in Korean Postmenopausal Osteoporotic Women
}

\author{
Yoon-Sok Chung $\cdot$ Sung-Kil Lim $\cdot$ Ho-Yeon Chung $\cdot$ In-Kyu Lee $\cdot$ \\ Il-Hyung Park · Ghi-Su Kim · Yong-Ki Min · Moo-Il Kang · Dong-Jin Chung • \\ Yong-Ki Kim · Woong Hwan Choi · Min Ho Shong · Ji-Hyun Park • \\ Dong-Won Byun · Hyun-Koo Yoon · Chan Soo Shin · Yil-Seob Lee • \\ Nam-Hee Kwon
}

Received: 7 June 2009/Accepted: 25 August 2009/Published online: 9 October 2009

(C) The Author(s) 2009. This article is published with open access at Springerlink.com

\begin{abstract}
Patient preferences, convenience, and bone turnover markers were evaluated for the monthly ibandronate over the weekly risedronate regimen in Korean postmenopausal osteoporotic women. This was a 6-month, prospective, randomized, open-label, multicenter study with a two-period and two-sequence crossover treatment design. After a 30-day screening period, eligible
\end{abstract}

This study was conducted as clinical trial of GSK Korea as protocol number 109393 .

\section{Y.-S. Chung}

Department of Endocrinology and Metabolism,

Ajou University School of Medicine, Suwon, Korea

S.-K. Lim $(\bowtie)$

Division of Endocrinology and Metabolism,

Department of Internal Medicine, Yonsei University College of

Medicine, 134 Shinchon-dong, Seodaemun-gu, Seoul 120-752,

South Korea

e-mail: 1sk@yumc.yonsei.ac.kr

H.-Y. Chung

Division of Endocrinology and Metabolism,

Department of Internal Medicine, KyungHee University,

Seoul, Korea

I.-K. Lee

Department of Internal Medicine,

Kyungpook National University School of Medicine,

Daegu, Korea

I.-H. Park

Department of Orthopedic Surgery, Kyungpook National

University School of Medicine, Daegu, Korea

G.-S. Kim

Division of Endocrinology and Metabolism,

Department of Internal Medicine, Asan Medical Center,

Seoul, Korea participants with postmenopausal osteoporosis were randomized to receive either monthly oral ibandronate $150 \mathrm{mg}$ for 3 months followed by weekly oral risedronate $35 \mathrm{mg}$ for 12 weeks (sequence A) or the same regimen in reverse order (sequence B). Patient preference and convenience were evaluated by questionnaire. The changes in serum Ctelopeptide after 3 months of treatment were analyzed. A total of 365 patients were enrolled in this study (sequence A 182, sequence B 183). Of patients expressing a preference $(83.4 \%), 74.8 \%$ preferred the monthly ibandronate

\section{Y.-K. Min}

Division of Endocrinology and Metabolism,

Department of Medicine, Samsung Medical Center,

Sungkyunkwan University School of Medicine, Seoul, Korea

M.-I. Kang

Division of Endocrinology and Metabolism,

Department of Internal Medicine, The Catholic University of

Korea, Seoul St. Mary's Hospital, Seoul, Korea

D.-J. Chung

Division of Endocrinology and Metabolism,

Department of Internal Medicine,

Chonnam National University Medical School, Gwangju, Korea

Y.-K. Kim

Division of Endocrinology and Metabolism,

Department of Internal Medicine, Pusan National University

College of Medicine, Pusan, Korea

W. H. Choi

Division of Endocrinology and Metabolism,

Department of Internal Medicine, Hanyang University,

Seoul, Korea

M. H. Shong

Division of Endocrinology and Metabolism,

Department of Internal Medicine, ChungNam National

University, Daejeon, Korea 
regimen over the weekly regimen $(25.2 \%)$. More women stated that the monthly ibandronate regimen was more convenient $(84.2 \%)$ than the weekly regimen $(15.8 \%)$. There was no significant difference in the change in bone turnover marker between the two treatments. The two regimens were similarly tolerable. There were fewer adverse events in the monthly ibandronate group compared to the weekly risedronate group in terms of gastrointestinal side effects (nausea and abdominal distension). This study revealed a strong preference and convenience for monthly ibandronate over weekly risedronate in Korean postmenopausal osteoporotic women. There was no significant difference in change of bone turnover marker and safety profile between the two regimens.

Keywords Ibandronate - Risedronate - Preference . Convenience $\cdot$ Korean

With the progressive aging of the world's population, osteoporosis has emerged as an important global health problem. Based on population growth and the current incidence of hip fractures in Asia, it is estimated that by $205050 \%$ of the world's hip fractures will occur in Asian women [1].

Bisphosphonates are regarded as the treatment of choice for postmenopausal osteoporosis and have proven clinical benefits, including a significantly reduced risk of vertebral and nonvertebral fractures in many clinical trials [2-6]. However, adherence to treatment among patients with postmenopausal osteoporosis is currently suboptimal, like

\section{J.-H. Park}

Division of Endocrinology and Metabolism,

Department of Internal Medicine, Chonbuk National University

Hospital, Jeonju, Korea

D.-W. Byun

Division of Endocrinology and Metabolism,

Department of Internal Medicine, SoonChunHyang University

Hospital, Seoul, Korea

H.-K. Yoon

Division of Endocrinology and Metabolism,

Department of Internal Medicine, Kwandong University College

of Medicine, Cheil General Hospital \& Women's Healthcare

Center, Seoul, Korea

C. S. Shin

Division of Endocrinology and Metabolism,

Department of Internal Medicine, Seoul National University

College of Medicine, Seoul, Korea

Y.-S. Lee

GlaxoSmithKline Korea, Seoul, Korea

N.-H. Kwon

GlaxoSmithKline Asia-Pacific, Singapore, Singapore in other chronic diseases $[7,8]$. Poor adherence leads to reduced clinical benefit, a raised incidence of secondary complications, and therefore increased health-care costs [7]. Data from a study evaluating adherence to bisphosphonate therapy show that the probability of continuing daily oral treatment is approximately $50 \%$ at 1 year [9]. This problem is largely contributed to the complex and inconvenient dosing instructions due to their low bioavailability and the potential for upper gastrointestinal (GI) side effects [8].

Patient treatment preference is an important factor in determining patient satisfaction with medical care and could provide an efficient way of maximizing the effectiveness of medical care [10]. Patient preferences for daily or weekly bisphosphonate therapy have been evaluated in prospective, open-label studies [11, 12]. Actually, numerous studies have proven that weekly dosing improves therapeutic adherence, though it remains suboptimal [13-15].

Ibandronate is a potent, new aminobisphosphonate with proven antifracture efficacy [2] and can be administered as a monthly regimen. A comparative study (Monthly Oral Iandronate in Ladies study [MOBILE]) demonstrated that monthly ibandronate was as effective and well tolerated as the currently approved daily ibandronate regimen in postmenopausal osteoporosis [6]. Furthermore, two randomized, multicenter clinical trials (the Bonviva Alendronate Trial in Osteoporosis [BALTO I and II]) found that significantly more women with postmenopausal osteoporosis preferred the monthly oral ibandronate regimen than the weekly alendronate regimen $[16,17]$. However, it is difficult to apply this result in Asian countries because both studies had populations that were only about $1 \%$ Asian. Moreover, there has been no randomized multicenter clinical trial comparing patient preference between ibandronate and risedronate, which is also widely prescribed for the treatment of osteoporosis. In addition, there were few studies comparing bone turnover markers between ibandronate and risedronate.

This study was aimed at determining whether the preference results of Caucasians are similar to those of Koreans. Other objectives were comparison of preference, convenience, and bone turnover marker between monthly ibandronate and weekly risedronate.

\section{Methods}

\section{Study Design}

This was a 6-month, prospective, randomized, open-label, multicenter, two-period, and two-sequence crossover study to investigate patient preference on dosing between oncemonthly ibandronate and once-weekly risedronate. The 
study design was similar to that used in previous studies (BALTO I and II) $[16,17]$ except that this study compared ibandronate with risedronate, not alendronate, and measured serum C-telopeptide of type I collagen (CTX) of participants both at baseline and 12 weeks after treatment to examine the change in bone turnover.

The study was conducted between March 2007 and May 2008 in 15 centers in South Korea and enrolled ambulatory women with postmenopausal osteoporosis who were bisphosphonate-naive. Participants were required to be able to understand and complete the Preference Questionnaire and to comply with the study protocol to be enrolled in this study. Women with upper GI disease such as reflux esophagitis uncontrolled with drugs or delayed esophageal emptying or active gastric/duodenal ulcer and who were unable to maintain an upright position for at least 60 minutes were excluded. Subjects who had hypersensitivity to ibandronate or risedronate; any other metabolic bone diseases but postmenopausal osteoporosis; any chronic diseases which could affect bone metabolism; or any abnormalities in laboratory parameters such as serum calcium, liver, or kidney function test and had been taking glucocorticoid were also excluded. All participants provided informed consent. The appropriate independent ethics committee or institutional review board approved the study protocol and all materials provided to participants.

After a 30-day screening period, eligible participants were randomized to take either monthly oral ibandronate $150 \mathrm{mg}$ (Bonviva; F. Hoffmann-La Roche Ltd, Basel, Switzerland) for 3 months followed by weekly oral risedronate $35 \mathrm{mg}$ (Actonel; Sanofi-Aventis Korea, Seoul, Korea) for 12 weeks (sequence A) or the same regimen in reverse order (sequence B) (Fig. 1). Central randomization was used to ensure similar distribution between the two sequences. There was no washout period between the two treatment regimens. The crossover in treatment regimens occurred after 3 months' treatment with ibandronate (sequence A) or 12 weeks' treatment with risedronate (sequence B). Additional safety information was collected 15 days after the end of treatment. Participants were educated to take both study medications in the morning after an overnight fast (6 hours or more), to keep an upright position (sitting or standing), and not to eat or drink fluids other than water for either 60 minutes or 30 minutes after taking ibandronate or risedronate, respectively. All participants received appropriate dosing and administration instructions and were reminded by telephone contact before each medication dosing schedule (ibandronate every month, risedronate every week). All women were supplemented with daily elemental calcium $500 \mathrm{mg}$ and vitamin D 125 IU (Oscal 500 D; Handok Pharmaceuticals, Seoul, Korea). Compliance was estimated by recording drugs dispensed versus drugs returned on the case record form. Adverse events and laboratory parameters were assessed by the study investigators. The use of clinically relevant concomitant medications was also recorded.

The primary end point of this study was patients' preference. The secondary end points were convenience and bone turnover marker level.

\section{Preference Questionnaire}

All participants were asked to answer the Preference Questionnaire at the end of the study (month 6) or when
Fig. 1 Study design and randomization schedule

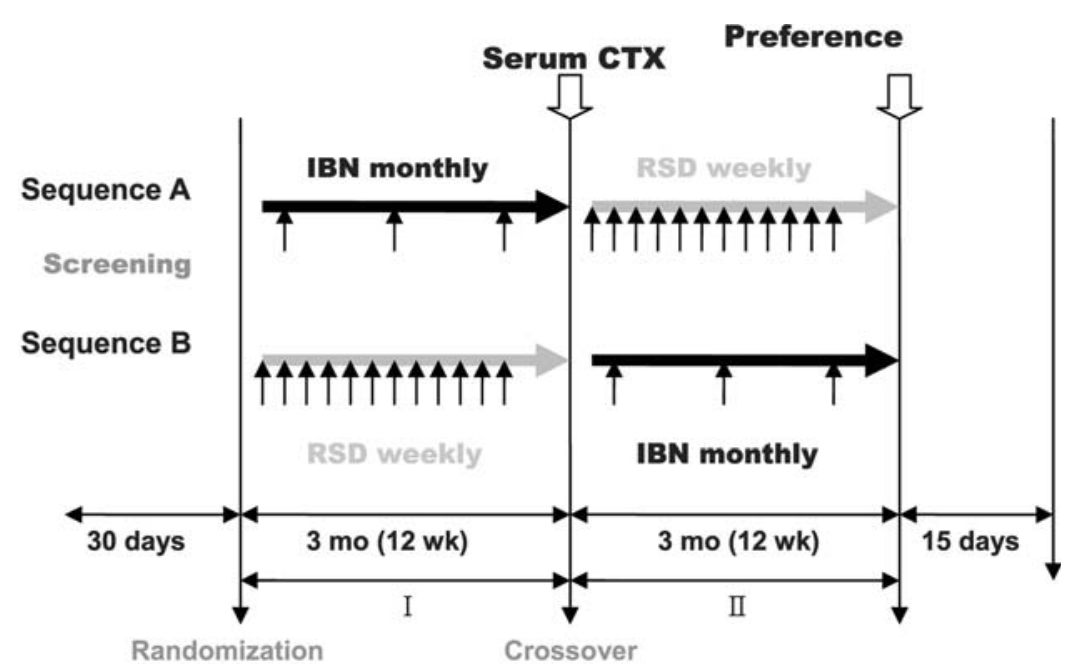

IBN = lbandronate

RSD = Risedronate

CTX $=$ C-telopeptide 
they withdrew from the study. The Preference Questionnaire was adapted from the BALTO I and II [16, 17]. If patients withdrew from the study before the crossover point, i.e., after having taken only the first treatment in the sequence, they were not requested to complete the questionnaire. If they withdrew after taking at least one dose of the second treatment in the sequence, they were asked to complete the questionnaire at the time of withdrawal. Patients were asked to complete the questionnaire by themselves before any other scheduled procedure at the visit and were not assisted in completing the questionnaire.

\section{Bone Turnover Marker}

Serum levels of CTX were measured at baseline and after 3 months of treatment. Blood samples for CTX assessments were taken at the end of the dosing interval ( 1 month after 3-month dosing of ibandronate, one week after 12-week dosing of risedronate), after an overnight fast of at least 6 hours, between 8:00 a.m. and 10:00 a.m., and processed at the central laboratory (Green Cross Reference Lab, Seoul, Korea). CTX levels were measured by electrochemiluminescence immunoassay (Modular Analytics, E170 Modular; Roche, Mannheim, Germany).

\section{Statistical Analysis}

The significance of preference and convenience was assessed, accounting for the potential effect of treatment order, using Gart's test [18] (excluding subjects with no preference) and Prescott's test [19] (including all preference and no preference data). Baseline and 3-month serum CTX levels between the two groups were analyzed with Student's $t$-test. The mean percentage changes in serum

Fig. 2 Disposition of subjects

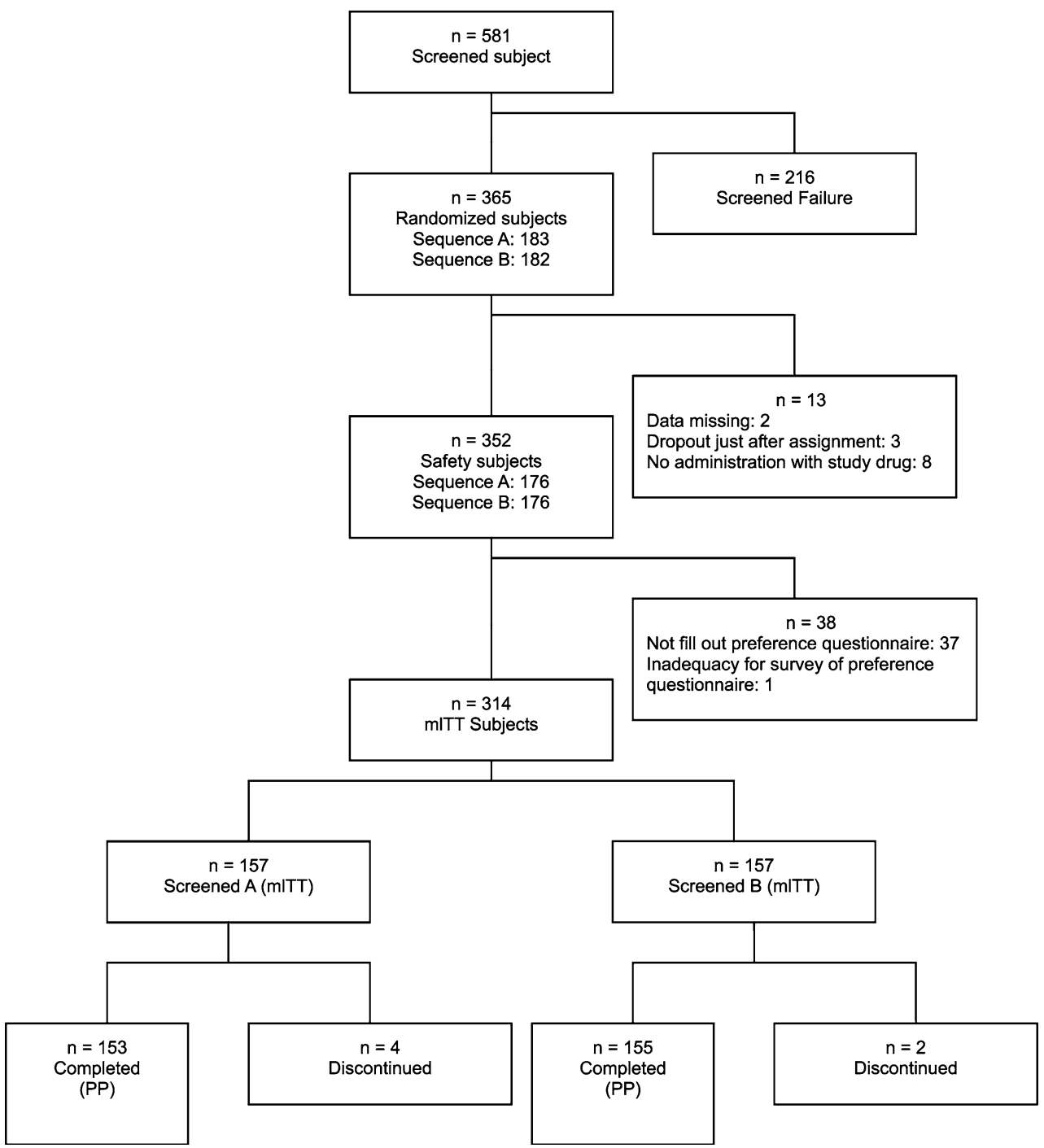


CTX (3 months - baseline values) between the two sequences were tested with ANCOVA and 95\% confidence interval. All the tests were two-sided, with a significance level of $P<0.05$.

\section{Results}

Patient Disposition and Baseline Characteristics

A total of 365 women were enrolled in this study; 182 were randomized to sequence $\mathrm{A}$ and 183 to sequence $\mathrm{B}$. The safety population (defined as patients who had received at least one dose of trial medication and had follow-up data end point) comprised 352 women included in the modified intention-to-treat population (Fig. 2).

Participants in sequence $\mathrm{A}$ and sequence $\mathrm{B}$ were well matched for age as well as weight, height, time since menopause, and time since diagnosis of postmenopausal osteoporosis (Table 1). There were no significant differences between sequences $\mathrm{A}$ and $\mathrm{B}$ in prior fragility fracture, family history of fragility fracture in a first-degree

Table 1 Patient demographics (safety population)

\begin{tabular}{|c|c|c|c|}
\hline Variable & $\begin{array}{l}\text { Sequence A } \\
(n=176)\end{array}$ & $\begin{array}{l}\text { Sequence B } \\
(n=176)\end{array}$ & $\begin{array}{l}\text { Total } \\
(n=352)\end{array}$ \\
\hline \multicolumn{4}{|l|}{ Age (years) } \\
\hline Mean & 61.3 & 62.0 & 61.7 \\
\hline Range & $48-79$ & $46-78$ & $46-79$ \\
\hline \multicolumn{4}{|l|}{ Height (cm) } \\
\hline Mean & 154.3 & 154.6 & 154.5 \\
\hline Range & $143-174$ & $141-170$ & $141-174$ \\
\hline \multicolumn{4}{|l|}{ Weight (kg) } \\
\hline Mean & 55.5 & 55.9 & 55.7 \\
\hline Range & $37-76$ & $36-81$ & $36-81$ \\
\hline \multicolumn{4}{|c|}{ Highest educational level } \\
\hline $\begin{array}{l}\text { Elementary } \\
\text { school }\end{array}$ & $47(26.7 \%)$ & $51(29.0 \%)$ & $98(27.8 \%)$ \\
\hline $\begin{array}{l}\text { Middle/high } \\
\text { school }\end{array}$ & $96(54.6 \%)$ & $73(41.5 \%)$ & $169(48.0 \%)$ \\
\hline $\begin{array}{l}\text { College/ } \\
\text { university }\end{array}$ & $10(5.7 \%)$ & $17(9.7 \%)$ & $27(7.7 \%)$ \\
\hline $\begin{array}{l}\text { Postgraduate } \\
\text { degree }\end{array}$ & $0(0.0 \%)$ & $1(0.6 \%)$ & $1(0.3 \%)$ \\
\hline Unknown & $23(13.1 \%)$ & $34(19.3 \%)$ & $57(16.2 \%)$ \\
\hline \multicolumn{4}{|c|}{ Current occupation } \\
\hline Working & $31(17.6 \%)$ & $27(15.3 \%)$ & $58(16.5 \%)$ \\
\hline Not working & $145(82.4 \%)$ & $149(84.7 \%)$ & $294(83.5 \%)$ \\
\hline \multicolumn{4}{|l|}{ Fracture history } \\
\hline Yes & $37(21.0 \%)$ & $34(19.3 \%)$ & $71(20.2 \%)$ \\
\hline
\end{tabular}

Sequence A: monthly ibandronate $\rightarrow$ weekly risedronate Sequence B: weekly risedronate $\rightarrow$ monthly ibandronate relative, and current smoking. The most common medications received by patients prior to study enrollment for the treatment of osteoporosis were estrogen and progestin (sequence A $34.5 \%$, sequence B $34.7 \%$ ).

\section{Preference}

Most women $(262 / 314,83.4 \%)$ preferred one of the two regimens to the other. Of the patients who reported a preference, $74.8 \%(196 / 262)$ preferred the monthly regimen of ibandronate and $25.2 \%$ (66/262) preferred the weekly regimen of risedronate. The preference rate for monthly ibandronate was statistically significant $(P<0.0001)$. Preference for monthly ibandronate was not affected by the order in which the women took the study medications (Gart order-effect $P=0.6210$ ). When data from all patients were included, i.e., including women who did not express a preference, 62.4\% (196/314) preferred monthly ibandronate dosing and $21.0 \%$ (66/314) preferred weekly risedronate dosing (Fig. 3). Again, the preference rate for monthly ibandronate was statistically significant $(P<0.0001)$.

The reasons identified by patients for their preference are detailed in Fig. 4 (patients could choose more than one reason). Of the $74.8 \%$ of participants who expressed a preference for the monthly ibandronate regimen, $77.6 \%(152 / 196)$ chose the greater ease of long-term adherence and $52.6 \%$ (103/196) a better lifestyle fit as a reason for their preference. The proportions of participants who mentioned less stomach discomfort and more easily tolerated side effects were $24.0 \%$ (47/196) and 22.0\% (43/196), respectively.

\section{Convenience}

Of the women expressing an opinion on convenience (229/ $314,72.9 \%), 84.2 \%$ found that the monthly ibandronate regimen was more convenient and $15.8 \%$ (43/272) found that the weekly risedronate regimen was more convenient. The convenience rate for monthly ibandronate dosing was statistically significant $(P<0.0001)$. This opinion was not

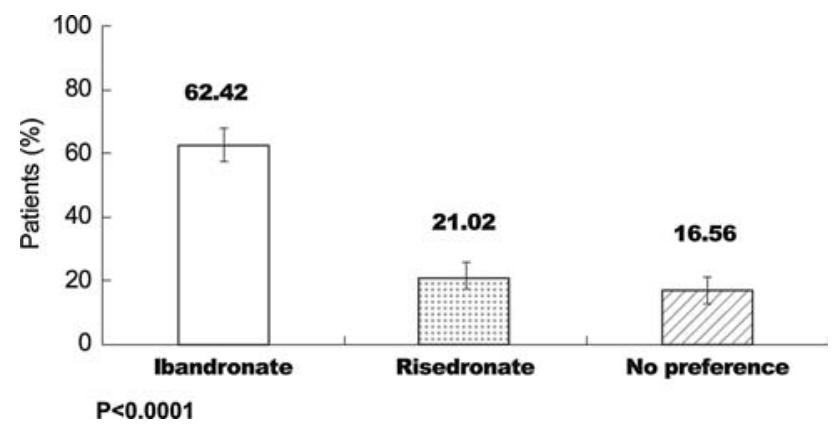

Fig. 3 Patient preferences for ibandronate monthly dosing over risedronate weekly dosing, including patients who did not express a preference for one treatment 
Fig. 4 Patient preferences and reasons for preference (excluding patients who did not state a preference for one treatment). Patients could provide more than one reason for preferring a particular regimen

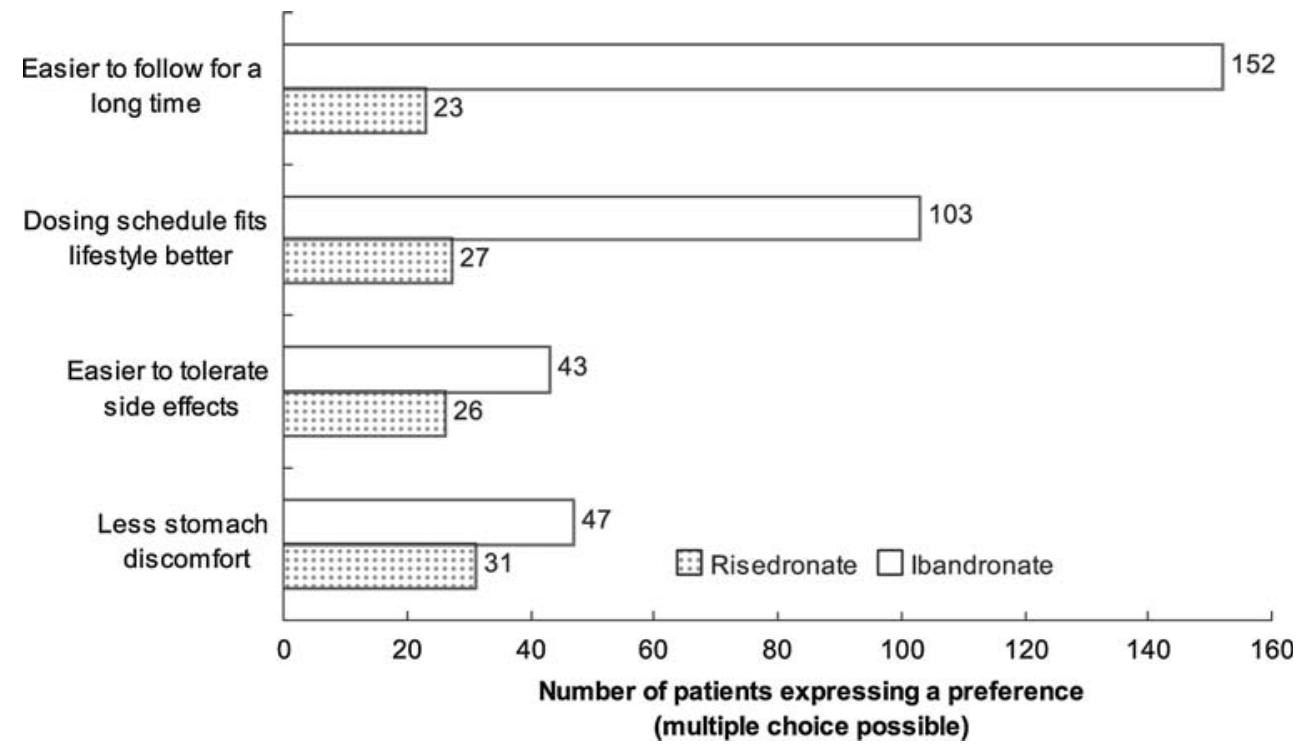

affected by treatment sequence (Gart order-effect, $P=$ 0.8814). Similar results were shown when the analysis included patients who did not express an opinion about treatment convenience (Fig. 5): The monthly ibandronate regimen was chosen by $72.9 \%$ of the overall study population and the weekly risedronate regimen was chosen by $13.7 \%$. Again, the convenience rate for monthly ibandronate was statistically significant $(P<0.0001)$.

\section{Compliance}

The compliance rate of the monthly ibandronate group was significantly higher than that of the weekly risedronate group $(P<0.01)$. The difference in compliance was relatively prominent at month 6 compared to month 3 (Table 2).

\section{Bone Turnover Marker}

There was no statistically significant difference between the monthly and weekly bisphosphonate groups in baseline

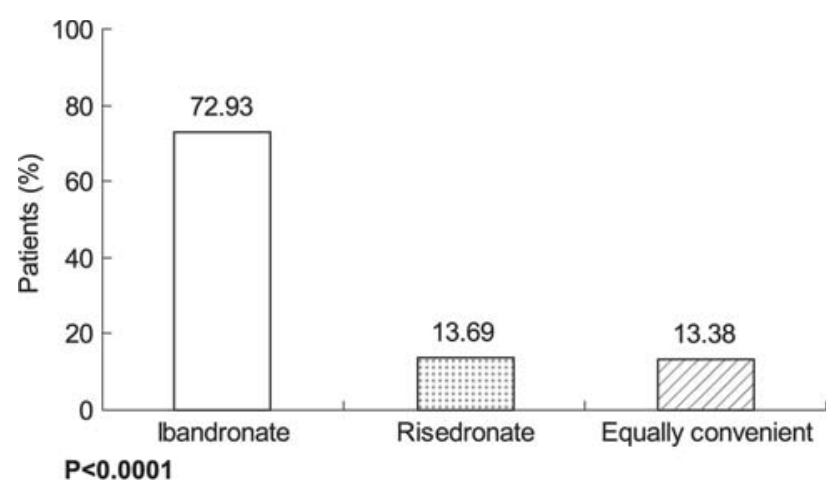

Fig. 5 Patients who found ibandronate monthly dosing more convenient than risedronate weekly dosing, including patients who did not express an opinion about convenience for one treatment and 3-month serum CTX levels. In addition, there was no statistical significant difference between the two treatment groups in mean percent change of serum CTX values (Table 3).

Safety

The incidence of adverse events was comparable between the two bisphosphonate regimens, with $41.0 \%$ and $40.1 \%$ of patients experiencing at least one event during ibandronate and risedronate treatment, respectively. Treatmentrelated adverse events were reported by $29.5 \%$ of patients during ibandronate treatment and $29.9 \%$ of patients during risedronate treatment. Treatment-related GI adverse events were reported by $19.4 \%$ of patients while taking ibandronate and $23.1 \%$ of patients while taking risedronate. More patients receiving once-weekly risedronate experienced abdominal distension and nausea $(6.9 \%$ vs. $3.3 \%$ and $6.9 \%$ vs. $3.0 \%$, respectively; $P<0.05$ ). Other frequent adverse events were generally comparable between patients receiving ibandronate and risedronate (Table 4). The incidence of adverse events resulting in withdrawal from the study was $4.2 \%(n=14)$ in patients receiving ibandronate and $4.5 \% \quad(n=15)$ in patients receiving risedronate. Clinically relevant changes in laboratory parameters were not observed in any patient during the study.

\section{Discussion}

Although bisphosphonates are regarded as the treatment of choice for postmenopausal osteoporosis, their poor adherence and persistence have limited their efficacy. It was known that patients preferred less frequent, simpler, and more convenient dosing regimens [20, 21]. A weekly 
Table 2 Compliance with study medication

\begin{tabular}{lcccc}
\hline & Ibandronate $n(\%)$ & Risedronate $n(\%)$ & Total $n(\%)$ & $P$ (exact test) \\
\hline Month 3 & & & & \\
$0-<50 \%$ & $3(1.9)$ & $1(0.6)$ & $4(1.3)$ & 0.0018 \\
$50-<100 \%$ & $1(0.6)$ & $12(7.7)$ & $13(4.1)$ & \\
$100 \%$ & $153(97.5)$ & $144(91.7)$ & $297(94.6)$ & \\
Total & $157(50.0)$ & $157(50.0)$ & $314(100.0)$ & \\
Month 6 & & & & \\
$0-<50 \%$ & $1(0.6)$ & $3(1.9)$ & $4(1.3)$ & $<0.0001$ \\
$50-<100 \%$ & $1(0.6)$ & $19(12.1)$ & $20(6.4)$ & \\
$100 \%$ & $155(98.7)$ & $135(86.0)$ & $290(92.3)$ & \\
Total & $157(50.0)$ & $157(50.0)$ & $314(100.0)$ & \\
\hline
\end{tabular}

Table 3 Changes in biochemical bone marker serum CTX

\begin{tabular}{llll}
\hline Serum CTX $(\mathrm{ng} / \mathrm{mL})$ & Ibandronate & Risedronate & $P(t$-test $)$ \\
\hline Baseline & & & \\
$n$ & 153 & 154 & \\
$\quad$ Mean \pm SD & $0.54 \pm 0.26$ & $0.50 \pm 0.23$ & 0.1861 \\
$\quad$ Range & $0.04-1.63$ & $0.12-1.62$ & \\
Month 3 & & & \\
$n$ & 153 & 155 & \\
$\quad$ Mean \pm SD & $0.21 \pm 0.16$ & $0.20 \pm 0.15$ & 0.4788 \\
$\quad$ Range & $0.02-0.97$ & $0.03-0.70$ & \\
Percent change & & & \\
$n$ & 153 & 154 & \\
$\quad$ Mean \pm SD & $-57.23 \pm 35.89$ & $-56.95 \pm 37.07$ & 0.9456 \\
Range & $-96.28-172.41$ & $-92.96-172.78$ & \\
\hline
\end{tabular}

Table 4 Summary of most frequent adverse events (AE)

\begin{tabular}{lcll}
\hline & $\begin{array}{l}\text { Ibandronate } \\
(n=336, \%)\end{array}$ & $\begin{array}{l}\text { Risedronate } \\
(n=334, \%)\end{array}$ & $P\left(\chi^{2}\right.$ test $)$ \\
\hline Gastrointestinal AE & $65(19.4)$ & $77(23.1)$ & 0.2402 \\
Dyspepsia & $25(7.4)$ & $24(7.2)$ & 0.8992 \\
Abdominal distension & $11(3.3)$ & $23(6.9)$ & 0.0332 \\
Nausea & $10(3.0)$ & $23(6.9)$ & 0.0194 \\
Abdominal pain & $10(3.0)$ & $5(1.5)$ & 0.1957 \\
Abdominal pain upper & $6(1.8)$ & $9(2.7)$ & 0.4266 \\
Gastroesophageal reflux & $7(2.1)$ & $7(2.1)$ & 0.9910 \\
Musculoskeletal AE & $63(18.8)$ & $50(15.0)$ & 0.1914 \\
Myalgia & $46(13.7)$ & $43(12.9)$ & 0.7556 \\
Arthralgia & $6(1.8)$ & $5(1.5)$ & 0.7687 \\
Nervous system AE & $17(5.1)$ & $18(5.4)$ & 0.8479 \\
Headache & $8(2.4)$ & $6(1.8)$ & 0.5969 \\
Dizziness & $7(2.1)$ & $5(1.5)$ & 0.5672 \\
\hline
\end{tabular}

dosing regimen has better therapeutic adherence than a daily dosing regimen in postmenopausal osteoporosis; however, it remains suboptimal [13-15]. Ibandronate is a potent, nitrogen-containing bisphosphonate which has been approved in Europe, the United States, and Korea to be given as a monthly regimen. The BALTO I and II studies reported that more women with postmenopausal osteoporosis preferred the monthly ibandronate regimen and expressed that the monthly ibandronate was more convenient than the weekly alendronate regimen [16, 17]. However, these findings cannot be applied in Asian countries because the participants in these studies included only about $1 \%$ Asian ethnicity. Furthermore, there have been few studies about preferences between monthly ibandronate and weekly risedronate, which have comparable efficacy and tolerability in treatment of osteoporosis [22-24]. This study has not only reconfirmed previous findings from the BALTO studies in Korea, an Asian country, but also proved that monthly ibandronate had better preference and convenience than weekly risedronate, similar to Western results, which was highly expected despite the different ethnicity.

One of the main reasons for noncompliance is the occurrence of adverse events [25]. In this study, the overall incidence of adverse events was similar between the two bisphosphonate regimens. The number of patients who were withdrawn from the study because of adverse events was also similar in both treatments. These results were also consistent with the previous BALTO studies.

Clinical trials evaluating the GI tolerability of bisphosphonates have found no significant differences in the incidence of spontaneously reported GI adverse events between placebo and bisphosphonates [2, 4, 26]. However, GI adverse symptoms have been reported with bisphosphonate use in the clinical setting and may be an important factor for discontinuing treatment [27-30]. BALTO I and II reported that the patients receiving both the monthly ibandronate and weekly alendronate regimens experienced similar GI adverse events. In this study, more patients receiving once-weekly risedronate experienced abdominal distension and nausea, though other GI adverse events occurred similarly in both treatments. 
In many clinical studies, monthly ibandronate showed a significant increase in bone mineral density (BMD) and a reduction in fracture risk [2, 6, 31]. Once-monthly ibandronate was shown to be clinically comparable to weekly alendronate at increasing BMD after 12 months in both the lumbar spine and total hip [32]. Furthermore, a retrospective cohort study found that patients treated with oral monthly ibandronate or weekly bisphosphonates (alendronate and risedronate) had similar low risks of hip fracture, nonvertebral fracture, and any clinical fracture. Ibandronate patients had a significantly lower relative risk of vertebral fracture than weekly bisphosphonate patients [33]. However, there were few studies comparing the change in bone turnover marker after treatment with monthly ibandronate and weekly bisphosphonates. In the present study, although it was of relatively short duration, both treatment regimens showed a similar percentage change of bone turnover marker.

Recently, a study reported that the monthly ibandronate regimen showed a better persistence rate with therapy than the weekly regimen, even though telephone contact was provided only to the monthly ibandronate group [34]. This study was not designed to assess the persistence of treatment. Further studies on monthly ibandronate persistence will be required in Asian countries.

In conclusion, this study confirmed the patient preference for monthly ibandronate over weekly bisphosphonates in Korean. Moreover, the present study indicates that the results previously reported vs. alendronate are also applicable to risedronate. Monthly ibandronate showed similar reduction of bone turnover marker compared to a weekly regimen. Patients with a monthly ibandronate regimen experienced fewer upper GI adverse events (nausea, abdominal distension) in this study.

Acknowledgement We thank Yong Jun Choi for manuscript preparation.

Open Access This article is distributed under the terms of the Creative Commons Attribution Noncommercial License which permits any noncommercial use, distribution, and reproduction in any medium, provided the original author(s) and source are credited.

\section{References}

1. Cooper C, Compion G, Melton LJ (1992) Hip fractures in the elderly: a worldwide projection. Osteoporos Int 2:285-289

2. Chesnut IC, Skag A, Christiansen C, Recker R, Stakkestad JA, Hoiseth A, Felsenberg D, Huss H, Gilbride J, Schimmer RC, Delmas PD (2004) Effects of oral ibandronate administered daily or intermittently on fracture risk in postmenopausal osteoporosis. J Bone Miner Res 19:1241-1249

3. Epstein S (2005) The roles of bone mineral density, bone turnover, and other properties in reducing fracture risk during antiresorptive therapy. Mayo Clin Proc 80:379-388
4. Harris ST, Watts NB, Genant HK, McKeever CD, Hangartner T, Keller M, Chesnut CH III, Brown J, Eriksen EF, Hoseyni MS, Axelrod DW, Miller PD (1999) Effects of risedronate treatment on vertebral and nonvertebral fractures in women with postmenopausal osteoporosis: a randomized controlled trial. Vertebral Efficacy with Risedronate Therapy (VERT) Study Group. JAMA 282:1344-1352

5. Liberman UA, Weiss SR, Broll J, Minne HW, Quan H, Bell NH, Rodriguez-Portales J, Downs RW Jr, Dequeker J, Favus M (1995) Effect of oral alendronate on bone mineral density and the incidence of fractures in postmenopausal osteoporosis. The Alendronate Phase III Osteoporosis Treatment Study Group. N Engl J Med 333:1437-1443

6. Miller PD, McClung MR, Macovei L, Stakkestad JA, Luckey M, Bonvoisin B, Reginster JY, Recker RR, Hughes C, Lewiecki EM, Felsenberg D, Delmas PD, Kendler DL, Bolognese MA, Mairon N, Cooper C (2005) Monthly oral ibandronate therapy in postmenopausal osteoporosis: 1-year results from the MOBILE study. J Bone Miner Res 20:1315-1322

7. World Health Organization (2003) Prevention and management of osteoporosis. World Health Organ Tech Rep Ser 921:1-164

8. Reginster JY, Rabenda V, Neuprez A (2006) Adherence, patient preference and dosing frequency: understanding the relationship. Bone 38:S2-S6

9. Lombas C, Hakim C, Znachetta JR (2001) Compliance with alendronate treatment in an osteoporosis clinic. J Bone Miner Res 15 Suppl 1:S529

10. Jahng KH, Martin LR, Golin CE, DiMatteo MR (2005) Preferences for medical collaboration: patient-physician congruence and patient outcomes. Patient Educ Couns 57:308-314

11. Kendler D, Kung AW, Fuleihan Gel H, Gonzalez Gonzalez JG, Gaines KA, Verbruggen N, Melton ME (2004) Patients with osteoporosis prefer once weekly to once daily dosing with alendronate. Maturitas 48:243-251

12. Simon JA, Lewiecki EM, Smith ME, Petruschke RA, Wang L, Palmisano JJ (2002) Patient preference for once-weekly alendronate $70 \mathrm{mg}$ versus once-daily alendronate $10 \mathrm{mg}$ : a multicenter, randomized, open-label, crossover study. Clin Ther 24:18711886

13. Bartl R, Goette S, Hadji P, Hammerschmidt T (2005) Persistence and compliance with daily and weekly administered bisphophonates for osteoporosis treatment in Germany. Osteoporos Int 16 Suppl 3:S45

14. Cramer JA, Amonkar MM, Hebborn A, Suppapanya N (2004) Does dosing regimen impact persistence with bisphosphonate theapy among postmenopausal osteoporotic women. J Bone Miner Res 19 Suppl 1:S448

15. Ettinger MP, Gallagher R, Amonkar M, Mahoney PM, Gilbride J (2004) Medication persistence is improved with less frequent dosing of bisphosphonates, but remains inadequate. Arthritis Rheum 50:S513

16. Emkey R, Koltun W, Beusterien K, Seidman L, Kivitz A, Devas V, Masanauskaite D (2005) Patient preference for once-monthly ibandronate versus once-weekly alendronate in a randomized, open-label, cross-over trial: the Boniva Alendronate Trial in Osteoporosis (BALTO). Curr Med Res Opin 21:1895-1903

17. Hadji P, Minne H, Pfeifer M, Bourgeois P, Fardellone P, Licata A, Devas V, Masanauskaite D, Barrett-Connor E (2008) Treatment preference for monthly oral ibandronate and weekly oral alendronate in women with postmenopausal osteoporosis: a randomized, crossover study (BALTO II). Joint Bone Spine 75:303-310

18. Gart JJ (1969) An exact test for comparing matched proportions in cross-over designs. Biometrika 56:75-80

19. Prescott RJ (1981) The comparison of success rates in cross-over trials in the presence of an order effect. Appl Stat 30:9-15 
20. Claxton AJ, Cramer J, Pierce C (2001) A systematic review of the associations between dose regimens and medication compliance. Clin Ther 23:1296-1310

21. Richter A, Anton SE, Koch P, Dennett SL (2003) The impact of reducing dose frequency on health outcomes. Clin Ther 25:23062335

22. Curtis JR, Westfall AO, Cheng H, Saag KG, Delzell E (2009) Risedronate and Alendronate Intervention over Three Years (REALITY): minimal differences in fracture risk reduction. Osteoporos Int 20:973-978

23. Takada J, Iba K, Imoto K, Yamashita T (2007) Changes in bone resorption markers among Japanese patients with postmenopausal osteoporosis treated with alendronate and risedronate. J Bone Miner Metab 25:142-146

24. Umland EM, Boyce EG (2001) Risedronate: a new oral bisphosphonate. Clin Ther 23:1409-1421

25. Kamatari M, Koto S, Ozawa N, Urao C, Suzuki Y, Akasaka E, Yanagimoto K, Sakota K (2007) Factors affecting long-term compliance of osteoporotic patients with bisphosphonate treatment and QOL assessment in actual practice: alendronate and risedronate. J Bone Miner Metab 25:302-309

26. Eisman JA, Rizzoli R, Roman-Ivorra J, Lipschitz S, Verbruggen N, Gaines KA, Melton ME (2004) Upper gastrointestinal and overall tolerability of alendronate once weekly in patients with osteoporosis: results of a randomized, double-blind, placebocontrolled study. Curr Med Res Opin 20:699-705

27. Hamilton B, McCoy K, Taggart H (2003) Tolerability and compliance with risedronate in clinical practice. Osteoporos Int 14:259-262
28. Lanza FL, Hunt RH, Thomson AB, Provenza JM, Blank MA (2000) Endoscopic comparison of esophageal and gastroduodenal effects of risedronate and alendronate in postmenopausal women. Gastroenterology 119:631-638

29. Rossini M, Bianchi G, Di Munno O, Giannini S, Minisola S, Sinigaglia L, Adami S (2006) Determinants of adherence to osteoporosis treatment in clinical practice. Osteoporos Int 17:914-921

30. Tosteson AN, Grove MR, Hammond CS, Moncur MM, Ray GT, Hebert GM, Pressman AR, Ettinger B (2003) Early discontinuation of treatment for osteoporosis. Am J Med 115:209-216

31. Delmas PD, Recker RR, Chesnut CH III, Skag A, Stakkestad JA, Emkey R, Gilbride J, Schimmer RC, Christiansen C (2004) Daily and intermittent oral ibandronate normalize bone turnover and provide significant reduction in vertebral fracture risk: results from the BONE study. Osteoporos Int 15:792-798

32. Miller PD, Epstein S, Sedarati F, Reginster JY (2008) Oncemonthly oral ibandronate compared with weekly oral alendronate in postmenopausal osteoporosis: results from the head-to-head MOTION study. Curr Med Res Opin 24:207-213

33. Harris ST, Reginster JY, Harley C, Blumentals WA, Poston SA, Barr CE, Silverman SL (2009) Risk of fracture in women treated with monthly oral ibandronate or weekly bisphosphonates: The Evaluation of Ibandronate Efficacy (VIBE) database fracture study. Bone 44:758-765

34. Cooper A, Drake J, Brankin E (2006) Treatment persistence with once-monthly ibandronate and patient support vs. once-weekly alendronate: results from the PERSIST study. Int J Clin Pract 60:896-905 